\title{
CHAPTER 18 \\ Climate Justice and Public Health: \\ Practical Ethics in Urgent Times
}

\author{
Fonna Forman
}

We are faced not with two separate crises, one environmental and the other social, but rather with one complex crisis, which is both social and environmental. Strategies for a solution demand an integrated approach to combating poverty, restoring dignity to the excluded, and at the same time protecting nature.

-Pope Francis, Laudato Si', 4, 139

Summary This chapter reflects on the disproportionate impact of climate change on the most vulnerable people and argues that the language of "climate justice" may not be the most effective language for communicating the urgency to the general public and for changing attitudes and behaviors around climate change. Drawing on theories of human motivation in the social sciences, the chapter argues that most people, most often, tend to be motivated by what most affects them, their families, their neighborhoods, and so forth. This suggests that focusing on the likely health impacts of climate change might be a more effective way of communicating with those who are not motivated by the narrative of social justice to change their attitudes and behaviors. Because the health impacts of climate change can be generalized to all of us, this is likelier to motivate a shift in attitudes in behavior among larger publics. The chapter concludes with reflections on how to integrate public health more effectively into our communications about climate change.

\footnotetext{
F. Forman $(\bowtie)$

Center on Global Justice, University of California, San Diego, La Jolla, CA, USA

e-mail: fonna@ucsd.edu
} 


\section{Climate Change and the Bottom Three Billion: Injustice, Not Misfortune}

There is a distinction in moral philosophy between injustice and misfortunate. A misfortune is something that happens through the fault of no one-an accident, a serendipitous catastrophe, the "way of the world" - a calamity that causes destruction and human suffering. But when does misfortunate become injustice? What if the calamity, for example, disproportionately harms those who are poor? And what if these already vulnerable victims of harm have little capacity to adapt? Moreover, let us imagine that there is a humanitarian response to the calamity but that it arrives more slowly and sporadically in the precarious zones than in the less precarious ones. This is a relevant theme following the hurricanes that tore through the Caribbean and southeastern portions of the USA early in the autumn of 2017. Let us imagine further that the harm caused by the calamity is not unpredictable or serendipitous at all; it is instead the result of human decision or neglect-a poorly or inadequately designed levy that breaks, for example, or crumbling infrastructure that finally fails, or building practices that ignore the risk of placing human settlements in vulnerable places. And let us imagine finally that the calamity is a longterm environmental impact of the behaviors and habits of a wealthy minority that make this type of calamity more frequent and the harms it inflicts on the poor more severe.

Where to draw the line between injustice and misfortune must be understood as a political act. As the late political theorist Judith Shklar (1990) noted,

We must recognize that the line of separation between injustice and misfortune is a political choice, not a simple rule that can be taken as a given. The question is, thus, not whether to draw a line between them at all, but where to do so ..." (Shklar, 1990, p. 5)

It is not uncommon in environmental politics that those responsible for causing harm and those asked to remediate it will try to characterize the harm as misfortune, with arguments like "calamities like this have always happened," "they have nothing to do with my actions," "they are the way of the world," "an act of nature," "an act of God," and so forth. And as power goes, those who cause environmental harm typically have more capacity and political agility than the victims of harm, who often are already vulnerable and marginalized from a society's circle of moral concern.

But let us be clear: the impacts of climate change on the most vulnerable people are not a misfortune; they are an injustice. The idea of climate justice embodies all of the disparities and gaps mentioned above, and many more. Climate justice is about an "adaptation gap" between rich and poor. It is about a "humanitarian response gap" between rich and poor. It is about a "planning gap." It is also about a "transparency gap," an "education gap," a "health access" gap," a "development gap," and an "energy access gap." And, most fundamentally, climate justice is about a "responsibility gap." Climate change is caused disproportionately by the production and consumption habits of the world's richest populations. The richest one 
billion people on the planet are responsible for about $50 \%$ of greenhouse gas emissions, while the poorest three billion, without access to affordable fossil fuels, are responsible for about 5\%. In contrast, the "bottom 3 billion" suffer the greatest harms associated with climate change (Dasgupta \& Ramanathan, 2014).

Climate change is projected to cause widespread and serious harm to human settlements on the planet, threatening to unravel many of the development gains of the last century (UNICEF, 2015). The effects of climate change cluster and bear down hard on the global poor, those who are both least responsible for the causes and who are least capable of adapting. The health impacts of climate change, particularly on the poor, are predicted to become catastrophic by midcentury if significant reductions in greenhouse gas emissions do not occur (Lancet Commissions, 2015).

The adaptation gap is perhaps most evident in the acceleration of climate-related human displacement in recent years. While metrics are still being refined to causally isolate climate change as a driver of migration, the United Nations Commission for Refugees (UNHCR) already predicted in 2009 that climate change would become the largest driver of population displacements both inside and across national borders (UNHCR, 2009). The global rate of displacement has more than doubled since 1970, from fewer than 2000 persons per million to more than 4000 persons per million in 2014 (NRC/IDMC, 2015, p. 22). The most commonly cited estimate is that 200 million people will be displaced by 2050 (IOM, 2008, pp. 11-12; Myers, 2005). These displacements, even if temporary, have a profound impact on individuals' lives, often involving the loss of a home or crops, and disproportionately harming individuals at the very bottom, who lack the resources to adapt and who become susceptible to human trafficking and forced labor.

In a recent paper on climate migration, Forman and Ramanathan (2018) paid special attention to the disproportionate impacts of slower progressive effects like droughts, soil erosion, forest loss, and the sea level rise (Forman \& Ramanathan, 2018). While extreme weather events often cause sudden mass displacements and are increasing in frequency, slower processes seem to have a stronger predictive effect on the likelihood of climate migration (McLeman, 2014). Those living in rural or low-lying coastal areas, whose livelihoods are linked with climate-sensitive sectors like agriculture and fishing, are the most vulnerable and at highest risk, as they are typically the least capable of either adapting in situ or migrating out, since the capacity to leave one's home entails certain financial and social capital such as education, language skills, and support networks (Biermann \& Boas, 2008).

In 1991, the Intergovernmental Panel on Climate Change (IPCC) predicted that climate change would accelerate urbanization in developing countries, with populations migrating from coastal lowlands-in particular, densely inhabited delta areas-to inland areas (IPCC, 1990). The world is now urbanizing at a rate of 32 million people each year, exerting unmanageable "demands on urban services" and "increasing political pressure on the state" (Barnett \& Adger, 2007, p. 642). In the developing world, rapid urbanization in recent decades has produced dramatic "asymmetrical" growth patterns as the poorest populations have amassed by the millions in precarious informal settlements, often periurban and along rivers and 
lagoons, uniquely exposing them to the effects of climate change-floods, drought, food and water shortages, and disease (Gadanho, 2014). The explosion of slums at the peripheries of cities across the planet is a humanitarian crisis of gargantuan proportion that cities in the developing world today are unprepared to confront (Davis, 2007). As we have witnessed in Syria, these climate-induced stressors can exacerbate civil unrest and even revolution (Kelly et al., 2015).

\section{Climate Justice: Redistributing Harms and Responsibilities}

Viewed through the lens of human suffering, climate change is not only an environmental crisis but also an ethical and political one. Climate justice demands that those who cause harm, and especially those who benefit from that harm, bear primary responsibility for remediating it and for preventing further harm in the future. In other words, climate justice has a temporal dimension that is both backward-looking and forward-looking. The wealthy, polluting population has an ethical responsibility to remediate human suffering in the present, accelerating aid to populations disproportionately struggling to adapt. The polluting population also has an ethical responsibility to mitigate future harm by doing everything necessary to mobilize a low-carbon global economy. This imperative includes helping developing populations leapfrog a carbon-based economy and tempering the promotion of our wasteful, petroleum-based lifestyle as the epitome of human happiness. It could be said that climate justice redistributes responsibilities and harms for the common good. The Mary Robinson Foundation-Climate Justice (MRFCJ), the first international organization committed to climate justice as a human right, frames this ethical mandate as "sharing benefits and burdens equitably" (MRFCJ, n.d.).

There has been perhaps no greater advocate in our generation for the cause of climate justice than Pope Francis in his encyclical letter, Laudato Si', of May 24, 2015. He has become a great ally in the integral fight against poverty, the fight for tolerance and human dignity, and the fight against climate change. In this now wellknown passage, he described the two-headed beast we are confronting:

Today we have to realize that a true ecological approach always becomes a social approach; it must integrate questions of justice in debates on the environment, so as to hear both the cry of the earth and the cry of the poor. (Pope Francis, Laudato Si', 1, 49)

After the release of Laudato Si', Pope Francis called for urgent coordinated action. It is not surprising that he began by convening mayors. Across the world, municipalities have led the way, demonstrating deeper commitment to coordinated climate action and social justice than nations, with agile, environmentally progressive mayors who know how to mobilize cross-sector partnerships and get things done (Barber, 2013). As the late political theorist and founder of the Global Parliament of Mayors, Benjamin Barber, put it, "Cities are the coolest political 
institutions on Earth"1 (Barber, 2017). The mayors who convened at the Vatican in July 2015 ended their meeting with a pledge, which urged world leaders to pass a

bold climate agreement that confines global warming to a limit safe for humanity, while protecting the poor and the vulnerable from ongoing climate change that gravely endangers their lives. (Pianigiani, 2015)

\section{Climate Justice: Latin American Living Laboratories}

I suspect there was also something distinctively Latin American about why Pope Francis began with mayors, a history with which he was quite familiar as a young Argentine. Latin American cities in recent decades have been particularly successful at transforming attitudes and behavior around climate change and environmental health while producing more equitable outcomes in the city-advancing social justice and climate justice together.

Some Latin American cities have become almost mythical as living laboratories of equitable green urbanization. The philosopher Antanas Mockus became the mayor of Bogota, Colombia, during its most intense period of violence in the late 1990s and early 2000s. It was a scene of social chaos and urban breakdown, unemployment, poverty, and choking air quality, the worst anywhere on the continent. People referred to Bogota as the most dangerous city on the planet. Mockus declared that urban transformation must begin with civic strategies designed to transform social behavior, to change hearts and minds. He became legendary for using arts, culture, and performance to dramatically reduce violence and lawlessness, reconnect citizens with their government and with each other, increase tax collection, reduce water consumption, and ultimately improve the quality of life for the poor. Shifting social norms and renewing public trust paved the way for Mayor Enrique Peñalosa's renowned TransMilenio bus rapid transit system, at the time the most advanced multinodal transportation system in the world, linking retrofitted bus lanes with bicycle hubs, cyclovia (bikeways), and dedicated walking paths that literally stitched that troubled city together. Bogota revolutionized public transportation in Latin America. What is notable here, however, is that shifting social norms came first; the infrastructure and environmental interventions followed (Forman \& Cruz, 2017; Forman, 2018). For Peñalosa, like Mockus before him, changing beliefs and social norms was essential to launching a successful egalitarian transportation agenda. He observed,

A developed country is not a place where the poor have cars; it is a place where the rich ride public transportation. (Peñalosa, 2014)

Mockus and Peñalosa emerged from a long tradition of participatory green urbanization across Latin America, stewarded by mayors who were committed to robust agendas of civic participation to ignite a sense of collective agency and dig-

\footnotetext{
${ }^{1}$ On the Global Parliament of Mayors, see https://globalparliamentofmayors.org/.
} 
nity among the poor, and ultimately to produce greener and more equitable cities: from the Worker's Party mayors in Porto Alegre, Brazil, who experimented with participatory budgeting in the 1980s; to Jaime Lerner in Curitiba, Brazil, who pioneered bus rapid transit and dozens of green interventions across the city; to the "social urbanism" of Mayor Sergio Fajardo in Medellín, Colombia, in the early 2000s, which transformed public spaces and green infrastructure into sites of education and citizenship building, and transformed Medellín into a global model of urban social justice (Forman \& Cruz, 2017, 2018; McGuirk, 2014). This tradition still thrives in cities across the continent, from La Paz to Quito to Mexico City, and carries important lessons for equitable green urbanization in cities across the world today.

\section{The Next Step: Public Health as a Social "Lever"}

The Bending the Curve report produced by the University of California in 2015 devoted a full chapter to the public health impacts of climate change, giving special emphasis to the idea of "climate justice" and the disproportionate public health impacts of global warming on the world's most vulnerable demographics. Titled "Bending the Curve and Closing the Gap," the chapter argued that climate change and global poverty are intricately intertwined and that they must be tackled simultaneously (Forman et al., 2016). We understood public health as an impact requiring urgent intervention. But we did not yet appreciate that public health predictions themselves could be deployed as a lever for social change, to stimulate changes in attitudes and behaviors about global warming and the urgencies we are all facing as a planet.

This section reflects further on the ethical implications of integrating public health more robustly as a mechanism for changing public opinion and expediting policy to keep global warming below $2{ }^{\circ} \mathrm{C}$, particularly among those demographics in wealthy, polluting societies that have proven themselves resistant to scientific or ethical arguments. Among the like-minded, we do not need to deploy arguments about the hardships of poverty or the fact that climate change complicates and deepens them. Those working on the front lines in the global health arena tend to be committed already, on ethical grounds, to remediating disproportionate impacts and urgently redistributing resources to assist vulnerable people. But when we engage publics and policy makers who disagree, passively or surreptitiously, we must become realists. Our ethics must become practical and strategic. We must be willing to travel alternative paths - paths that are ethically incomplete, partial, incremental, and circuitous. When the harms we seek to address are severe and urgent, and when tipping points are in sight, ideals can become a hindrance. As development economist Amartya Sen has long argued, we need to welcome "partial realizations" in times of urgency, since ethical compromises can save lives and reduce human suffering. This was the central theme of his 2009 book, The Idea of Justice, which 
sought to chasten the more idealistic and transcendental theories of global justice associated with John Rawls and his followers:

I would like to wish good luck to the builders of a transcendentally just set of institutions for the whole world, but for those who are ready to concentrate on reducing manifest injustices that so severely plague the world, the relevance of a merely partial ranking [of distributional priorities] for a theory of justice can actually be rather momentous. (Sen, 2009, p. 263)

When we speak to publics and politicians today who are not motivated by altruistic or collective ends, who do not share our distributional priorities (to use Sen's language), and who through habit or agenda are inured to the status quo, we must find the right "lever" to turn them as they are, in very practical ways, toward the ends we seek. We can motivate change at the margins, along ethical lines, when the opportunity costs are low enough. But more fundamental societal changes in attitudes and behavior require a shift in how we communicate.

We know, for example, that people become more receptive to climate-friendly public policy when they better understand the specific impacts of climate change on their own lives and communities (Furth \& Gantwerk, 2013; Pincetl, 2010). A study of attitudes and behaviors among residents of low-lying coastal communities in South Florida, commissioned by the Union of Concerned Scientists, found that climate-friendly attitudes and behaviors are likelier when the negative effects of climate change are made concrete and relevant for people, rather than something far-off like melting ice caps and polar bears. Researchers have found that when people understand precisely how the sea level rise will affect their own city and their own neighborhood, their attitudes change (Cosgrove, 2012). They are likelier to be receptive to the concept of global warming and supportive of local climate-friendly public policy. This was even true for a majority of individuals self-described as politically "conservative." Second, the same study found that people are likelier to change their behaviors as well—not just beliefs but behaviors too-when concrete opportunities for local climate action are made available to them. Knowing the risks without having opportunities to act can produce paralysis, so the conclusion from public opinion research is Go Local: Start with Impact, End with Action.

Given this, it seems we will be more effective if we reframe our message about climate change from a language of duty to a language of prudence, from a language of climate justice (which motivates only those who are already religiously, ethically, or publicly inclined to change their behavior for the betterment of the least well-off) to a language of personal and local well-being, and from a language of the other to a language of the self. Climate justice is a language of disproportionate impact and blame, and it is not the best vehicle for instigating broad social change. Those who are already immune to the urgencies of human suffering, and to the appeals of social justice sui generis, will not be moved by the addition of a threat multiplier like climate change. In fact, as noted at the beginning of this chapter, the language of climate justice can trigger defensive retrenchment in some audiences and ethical back peddling into the mindset of "misfortune." 
The early modern idea of "enlightened self-interest" can be instructive here. In The Passions and the Interests, Albert Hirschman explored the way early modern thinkers used the idea of "enlightened self-love" as a motivational proxy for altruism (Hirschman, 1977). This helps explain why individuals sometimes sacrifice immediate benefits for social or collective ends though they are not motivated by social or collective reasons to do so. Starting with a realist's concession that only a small subset of us will be reliably motivated by altruism, selfish individuals nevertheless can produce pro-social ends by exercising prudence, or foresight, to pursue interests that coincide with the interests of others; in a selfish world, private and public can still converge. Prudence can restrain present gratification for greater gratification in the future.

The idea of enlightening selfishness is obviously not new to the climate change discussion. The use of carrots rather than sticks to motivate climate-friendly behavior is one of California's great, though sometimes controversial, success stories ("cap-and-trade") for the ethical compromises incentives always entail.

But along these lines of thinking about carrots, why not also think creatively about another powerful motivation: the personal health risks of climate change. Maria Neira suggests (see Chap. 8 in this book) that we frame climate change not as an environmental crisis but as a public health crisis. This section concludes with five thoughts about this.

First, we need to convince people and politicians where their true interests lie. This requires a pervasive shift in our norms (Griskevicius et al., 2008). "Mitigating climate change" needs to become synonymous in people's minds with "preserving health and well-being"-for me, and for all. According to a 2017 Gallup poll, only $42 \%$ of Americans presently believe that climate change will pose a serious threat in their lifetime (Saad, 2017). We need to increase public knowledge about very concrete and broad public health threats in order to enlighten self-interest.

Second, relatedly, we need to "equalize impacts" as a matter of practical ethics, to stimulate a more generalized sense of public urgency. Focusing on health disparities for the poor does not get us there. We need to talk about the relation of air quality, for example, to stroke, cardiovascular disease, respiratory disease, and so forth. This is a powerful equalizing tool. Advancing the idea that we are all in peril, regardless of our wealth and social position, expansion of the circle of potential victimhood is a powerful equalizing tool. Again, those of us committed to climate justice need to make compromises like this. We are distraught over the disparities in our world. But the language of disparity and ethical duty to others does not move people who are already numb to global justice. We need to be strategic.

Third, we need to think about who is best situated to communicate public health risks. The issue of public trust here is essential. In our brave new fact-free world, politicians, journalists, scientists, and intellectuals have all been castigated as biased, corrupt, detached from reality, and untrustworthy. This may be a very American (and indeed increasingly European) phenomenon, but these are the populations we are struggling to reach. Faith leaders have been effective messengers in some places, framing the perils of climate change through scriptural inspiration, respect for Mother Earth, and divine compassion for our fellow creatures. Religious 
communities can also help to promote new social norms among their ranks-an important dimension of sustainable behavioral shift, since norms always have a social regulatory component. The argument here is that public health might help us intervene at even broader scales, motivating through different channels, by tapping into very conventional concerns about personal health and well-being, and moving people from what they love-not Mother Earth, not common humanity, but their well-being and the well-being of those they love.

To accomplish this, fourth, health practitioners will need to get on board. For the most part they have been less publicly tarnished than the other relevant professions. And health practitioners are also capable of engaging people where they are: in the intimacy of an examination room. It may well be that the general practitioner (GP) the pediatrician, the obstetrician/gynecologist, the midwife, and the nurse practitioner are our most important soldiers on the ground right now and potentially our most effective climate educators.

This entails, fifth, an important shift in the way we train our health professionals today - practitioners as well as researchers, policy makers, and community-based activists - in the public health arena. Medical schools and public health institutes will need to become increasingly more collaborative, interdisciplinary, community engaged, and better insulated from corporate agendas. They will need to commit themselves to integrating environmental health education, and policy agendas more explicitly into their mission.

Take, for example, the Community Stations at the University of California San Diego, a network of research and teaching stations (located in four disadvantaged neighborhoods on both sides of the US-Mexico border) that focus on communityengaged climate action and environmental health education. ${ }^{2}$ At these sites, teaching and research are conducted collaboratively with local environmental nonprofit organizations. The Community Stations are committed to three main public health agendas: (1) providing community-based environmental health education for university students, teaching them to become climate communicators and educators; (2) increasing environmental health literacy among adults and especially children in partner communities (with the idea that educating children is our most essential task); and (3) stewarding participatory climate action at the neighborhood scalefrom small-scale activities (like raising awareness of consumption habits and stimulating a walking and cycling culture) to designing and financing zero-net energy solutions and retrofits of homes, schools, and businesses.

One of these stations, the EarthLab Community Station, is located in Encanto, San Diego's most challenged inner-city neighborhood, and situated near Chollas Creek, the city's most polluted waterway. ${ }^{3}$ EarthLab is a 4-acre outdoor environmental classroom with community gardens, solar houses, water-harvesting facili-

\footnotetext{
${ }^{2}$ Led by the author in collaboration with Teddy Cruz, Professor of Public Culture and Urbanism at the University of California, San Diego.

${ }^{3}$ EarthLab is a partnership between the University of California, San Diego, the Encanto-based environmental nonprofit organization Groundwork San Diego, and the San Diego Unified School District. For further discussion, see Forman et al. (2016).
} 
ties, an energy "nanogrid," and other green infrastructure designed by university researchers as learning tools for the six public schools within walking distance of the site. Thousands of low-income youth and their families circulate through EarthLab each year, learning about the public health effects of climate change and environmental degradation in their own neighborhoods and participating in climate action in concrete ways.

This is highly replicable and scalable activity. This project began as an experimental coalition between a university, a school district, and a community-based environmental nonprofit organization-precisely the kind of integral action Pope Francis advocated in Laudato Si'. Universities everywhere, large and small, are positioned to facilitate this kind of local collaborative work for the benefit of students, local communities, and the planet.

\section{Conclusion}

This chapter acknowledges the urgent and disproportionate impact of climate change on the bottom three billion among us. But it argues that the language of climate justice is not the most effective framework for communicating about climate change to the larger public. Those who are not receptive to social justice sui generis will not be motivated to change their attitudes and behaviors about climate change on the grounds that it disproportionately harms the vulnerable. The chapter argues that most people are motivated most often by what most impacts themselves, their families, and their neighborhoods. This suggests that a more generalizable language about the health impacts of climate change might be a more effective way of communicating with those who are not motivated by the narrative of social justice to change their attitudes and behaviors. The chapter closes with some reflections about who is best positioned to communicate these impacts. The takeaway from these reflections is that those of us who are committed to mitigating climate change to lessen the impacts on the most vulnerable ought to consider that narratives about generalizable health impacts might just be a more expeditious path toward the ends we are seeking.

\section{References}

Barber, B. (2013). If mayors ruled the world: Dysfunctional nations, rising cities. New Haven: Yale University Press.

Barber, B. (2017). Cool cities: Urban sovereignty and the fix for global warming. New Haven: Yale University Press.

Barnett, J., \& Adger, W. N. (2007). Climate change, human security, and violent conflict. Climate Change and Conflict, 26, 639-655. https://doi.org/10.1016/j.polgeo.2007.03.003 
Biermann, F., \& Boas, I. (2008). Protecting climate refugees: The case for a global protocol. Environment: Science and Policy for Sustainable Development, 50, 8-17. https://doi. org/10.3200/ENVT.50.6.8-17

Cosgrove, T. (2012). Memo on "Sea Level Rise Focus Groups," Union of Concerned Scientists.

Dasgupta, P., \& Ramanathan, V. (2014). Pursuit of the common good: Religious institutions may mobilize public opinion and action. Science, 345. https://doi.org/10.1126/science.1259406

Davis, M. (2007). Planet of slums. London: Verso.

Forman, F. (2018). Social norms and the cross-border citizen: From Adam Smith to Antanas Mockus. In C. Tognato (Ed.), Cultural agents reloaded: The legacy of Antanas Mockus (pp. 333-356). Cambridge, MA: Harvard University Press.

Forman, F., \& Cruz, T. (2017). Latin America and a new political leadership: Experimental acts of co-existence. In J. Burton, S. Jackson, \& D. Wilsdon (Eds.), Public servants: Art and the crisis of the common good (pp. 71-90). Boston, MA: MIT Press.

Forman, F., \& Cruz, T. (2018). Global justice at the municipal scale: The case of Medellín, Colombia. In L. Cabrera (Ed.), Institutional cosmopolitanism (pp. 189-215). New York: Oxford University Press.

Forman, F., \& Ramanathan, V. (2018). Climate change, mass migration and sustainability: A probabilistic case for urgent action. In M. Suarez-Orozco (Ed.), Humanitarianism and mass migration (pp. 42-59). Oakland, CA: University of California Press.

Forman, F., Solomon, G., Morello-Forsch, R., \& Pezzoli, K. (2016). Bending the curve and closing the gap: Climate justice and public health. Collabra, 2, 22. https://doi.org/10.1525/collabra.67

Furth, I., \& Gantwerk, H. (2013). Citizen dialogues on sea level rise: Start with impacts/end with action. San Diego, CA: Viewpoint Learning. Retrieved February 9, 2020 from https://climateaccess.org/system/files/Viewpoint\%20UCS_sea\%20level\%20dialogues.pdf

Gadanho, P. (2014). Uneven growth: Tactical urbanisms for expanding megacities. New York, NY: Museum of Modern Art.

Griskevicius, V., Cialdini, R. B., \& Goldstein, N. J. (2008). Social norms: An underestimated and underemployed lever for managing climate change. International Journal for Sustainability Communication, 3, 5-13.

Hirschman, A. O. (1977). The passions and the interests: Arguments for capitalism before its triumph. Princeton: Princeton University Press.

IOM (International Organization for Migration) (2008). Migration and climate change (IOM migration research series) (31st ed.). Geneva: IOM.

IPCC (Intergovernmental Panel on Climate Change) (1990). Climate change: The IPCC impacts assessment (pp. 5-11). Canberra: IPCC.

Kelley, C. P., Mohtadib, S., Canec, M. A., Seagerc, R., \& Kush-Nirc, Y. (2015). Climate change in the Fertile Crescent and implications of the recent Syrian drought. Proceedings of the National Academy of Sciences of the United States of America, 112, 3241-3246.

Lancet Commissions (2015). Health and climate change: policy responses to protect public health. Lancet, 386, 1861-1914.

Mary Robinson Foundation-Climate Justice (MRFCJ) (n.d). Retrieved February 9, 2020 from https://www.mrfcj.org/principles-of-climate-justice/share-benefits-and-burdens-equitably/

McGuirk, J. (2014). Radical cities: Across Latin America in search of a new architecture. London: Verso.

McLeman, R. A. (2014). Climate and human migration: Past experiences, future challenges. Cambridge, UK: Cambridge University Press. Retrieved February 9, 2020 from www.cambridge.org/core/books/climate-and-humanmigration/0D0D207E8BA3D169452A84FEB7D77 $9 \mathrm{CB}$

Myers, N. (2005). Environmental refugees: An emergent security issue, 13th Economic Forum, May 2005, Prague.

NRC/IDMC (Norwegian Refugee Council and Internal Displacement Monitoring Centre) (2015). Global estimates 2015: People displaced by disasters. Geneva: IDMC. 
Peñalosa, E. (2014). Why buses represent democracy in action (TED talk). Retrieved February 9, 2020 from https://www.ted.com/talks/enrique_penalosa_why_buses_represent_democracy_in_ action

Pianigiani, G. (2015). At Vatican, mayors pledge climate change fight. New York Times, July 21, 2015.

Pincetl, S. (2010). Implementing municipal tree planting: Los Angeles million-tree initiative. Environmental Management, 45, 227-238.

Pope, F. (2015) Laudato Si (Encyclical letter on care of our common home). Retrieved February 9, 2020 from http://www.vatican.va/content/francesco/en/encyclicals/documents/papa-francesco_20150524_enciclica-laudato-si.html

Ramanathan, V., Allison, J., Auffhammer, M., Auston, D., Barnosky, A. D., Chiang, L., et al. (2015). Chapter 1. Bending the curve: Ten scalable solutions for carbon neutrality and climate stability. Collabra, 2, 15. Oakland: University of California Press. Retrieved February 9, 2020 from https://doi.org/10.1525/collabra.55

Saad, L. (2017). Global warming concern at three-decade high in US. Gallup. Retrieved February 9, 2020 from https://news.gallup.com/poll/206030/global-warming-concern-three-decadehigh.aspx

Sen, A. (2009). The idea of justice. Belknap: Harvard.

Shklar, J. (1990). Faces of injustice. New Haven: Yale.

UNHCR (2009). Climate change could become the biggest driver of displacement: UNHCR Chief. Retrieved February 9, 2020 from http://www.unhcr.org/en-us/news/latest/2009/12/4b2910239/ climate-change-become-biggest-driver-displacement-unhcr-chief.html

UNICEF (United Nations Children's Fund) (2015). Children will bear the brunt of climate change. Retrieved February 9, 2020 from www.unicef.org/media/media_86347.html

Open Access This chapter is licensed under the terms of the Creative Commons Attribution 4.0 International License (http://creativecommons.org/licenses/by/4.0/), which permits use, sharing, adaptation, distribution and reproduction in any medium or format, as long as you give appropriate credit to the original author(s) and the source, provide a link to the Creative Commons license and indicate if changes were made.

The images or other third party material in this chapter are included in the chapter's Creative Commons license, unless indicated otherwise in a credit line to the material. If material is not included in the chapter's Creative Commons license and your intended use is not permitted by statutory regulation or exceeds the permitted use, you will need to obtain permission directly from the copyright holder. 